\title{
THE FUTURE OF COAL CONSUMPTION IN A CARBON CONSTRAINED WORLD
}

\author{
James R. McFarland ${ }^{1,2}$, Howard J. Herzog ${ }^{1}$, and Henry D. Jacoby ${ }^{2}$ \\ ${ }^{1}$ Laboratory for Energy and the Environment, M.I.T., Cambridge, MA 02139, USA \\ ${ }^{2}$ Joint Program on the Science and Policy of Global Change, M.I.T. Cambridge, MA 02139, USA
}

\begin{abstract}
Coal accounts for nearly $30 \%$ of all global fossil fuel consumption and $37 \%$ of fossil fuel emissions of carbon dioxide. It is used primarily in the electric power sector where it provides over half of the primary energy input. In the absence of penalties or restrictions on carbon dioxide emissions, coal use for electricity generation is expected to grow over the course of this century due to its relative abundance. However, policies to reduce carbon dioxide emissions have the potential to threaten coal's dominance in the electric power sector in favor of less carbonintensive natural gas. Carbon dioxide capture and storage (CCS) technologies hold promise in offsetting this switch. To understand these tradeoffs in a carbon dioxide constrained world, we examine the influence of four factors on future of coal consumption in the electric power sector: the price of carbon emissions, the price of natural gas, costs of CCS technologies, and the dispatch between coal and natural gas generation technologies. In this paper, we develop plausible, yet wide-ranging, scenarios for the variables mentioned above. We assess their effect on coal consumption using a computable general equilibrium model of the world economy, the MIT Emissions Prediction and Policy Analysis (EPPA) model. The results illustrate how competing technologies, changing input prices, and general equilibrium effects influence the adoption of CCS technologies. Our results for the United States and Europe suggest that carbon price and dispatch have the most significant effect on future coal consumption. Improvements in CCS technology costs make coal consumption less dependent on gas price, but do not mitigate the carbon price effects on consumption through 2050.
\end{abstract}

\section{Introduction}

Over this century, in the absence of penalties or restrictions on carbon dioxide emissions, coal use for electricity generation is expected to grow to $75 \%$ of the fossil energy input to the electric power sector due to its low price relative to other fossil fuels. Comprising close to $90 \%$ of conventional fossil resources, the price of coal should remain more constant than that of natural gas, the second major source of primary energy input for electric power. However, policies to reduce carbon dioxide emissions have the potential to threaten coal's dominance in the electric power sector in favor of less carbon-intensive natural gas and renewables. Carbon dioxide capture and storage (CCS) technologies hold promise in offsetting a fuel switch away from coal. To determine what role coal may play in a transition to lower carbon-emitting energy sources, this paper explores the influence of four factors on future of coal consumption in the electric power sector: the price of carbon, the price of natural gas, costs of CCS technologies, and the economic dispatch between coal and natural gas generation technologies.

This analysis emphasizes the time frame to 2050 and highlights results for the US and Europe. Although one may expect new, low carbon-emitting generating technologies to be available in 2050, their proportion of the installed generating capacity of the electric power system will yet be small by this time. It is therefore reasonable to assume that our energy systems will still be dominated by fossil fuels. This sets up a competition between coal and natural gas, the key fossil fuels used in electricity generation. The US and Europe account for nearly a third of global coal consumption. Furthermore, the electric power sector consumes over $95 \%$ of the coal used in the US and over $80 \%$ of the coal consumed in Europe.

The first section describes the modeling methodology and scenarios used to examine the consumption of coal. The effects of carbon prices, gas prices, technology costs, and economic dispatch are presented in the second section followed by conclusions.

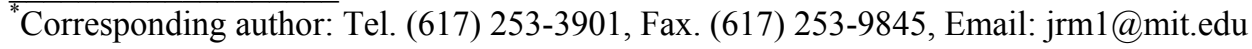




\section{Methodology}

The MIT Emission Prediction and Policy Analysis (EPPA) model is used to examine the sensitivity of coal consumption in the US and European electric power sectors to carbon prices, natural gas prices, and technology costs. In this assessment, each of these three variables is examined over a broad range of values. As stated at the outset, although developments in renewable and nuclear technologies are highly likely over this time frame, it is doubtful that they will have gained significant market share by 2050. This simplification would not hold after 2050 .

\section{The MIT EPPA Model}

The EPPA model is a recursive dynamic multi-regional computable general equilibrium model of the world economy developed for the analysis of climate change policy. Version 4 of the model used in this analysis has been updated in a number of ways from Version 3 documented by Babiker et al.[1]. It includes non- $\mathrm{CO}_{2}$ GHGs, greater disaggregation of technologies in the electric sector, and updated evaluation of economic growth and resource availability $[2,3,4]$. Version 4 is built on a comprehensive energy-economy data set, GTAP-5E, that accommodates a consistent representation of energy markets in physical units as well as detailed accounts of regional production and bilateral trade flows [5]. The base year for the model is 1997, and it is solved recursively at 5-year intervals through 2100 to capture the long-term dynamics of resource scarcity and capital stock turnover. Version 4 of EPPA also contains further regional disaggregation into 16 regions. Only the US and Europe are reported in this analysis.

The production structure of the model consists of both energy and non-energy sectors. The non-energy production sectors include agriculture, energy intensive industry, other industries, and services. Extant energy production sectors are crude oil, refined oil, coal, natural gas, and electricity. The greatest technology disaggregation occurs in the electric power. Added to the three technologies now in widespread use (conventional fossil, nuclear, and hydroelectric) are five technologies that may take substantial market share in the future. These include two renewable technologies: biomass and a combined wind and solar technology, and three additional fossil technologies: natural gas combined cycle (NGCC or advanced gas), NGCC with capture and sequestration (gas capture), and integrated gasification combined cycle with capture and sequestration (coal capture) [3]. The generation of electricity via nuclear power is assumed to be constant over the modeling horizon.

\section{Carbon price scenarios}

The effect of carbon prices on coal consumption is examined under three carbon price paths. The price paths are applied uniformly across all regions beginning at low, politically plausible levels in 2010 and rising over time. In the low price path scenario, carbon emissions are penalized at $\$ 10 / \mathrm{tC}$ beginning in 2010 and initially rise by $9 \%$ per year and stabilize at $\$ 300 / \mathrm{tC}$ by 2100 (see Figure 1). A mid price path scenario begins at a more aggressive $\$ 20 / \mathrm{tC}$ and rises $10.5 \%$ per year to reach $\$ 340 / \mathrm{tC}$ in 2050 . This price path approaches $\$ 450 / \mathrm{tC}$ in 2100 . The high price path scenario also begins at $\$ 20 / \mathrm{tC}$ and grows to $\$ 500 / \mathrm{tC}$ by 2050 .

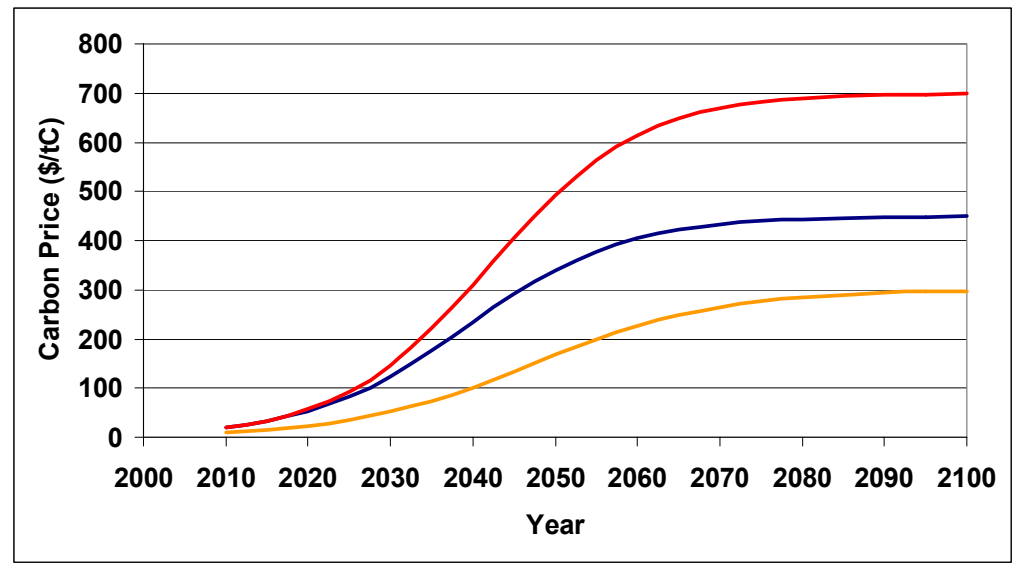

Figure 1 High, mid, and low carbon price paths (2050 and 2100 prices shown) 
The prices escalate faster than economic growth, which helps to curtail emissions. US carbon emissions stabilize at $2.4 \mathrm{GtC} / \mathrm{yr}$ and $2.0 \mathrm{GtC} / \mathrm{yr}$ for the low and high scenarios, respectively. None of the price paths stabilize atmospheric carbon concentrations.

\section{Gas price scenarios}

The effect of gas prices on coal consumption is analyzed under three scenarios (reference, mid, and low). Version 4 of EPPA was modified to treat natural gas as readily tradable, homogenous commodity with a global price, similar to crude oil. This offers two benefits. First, the effect of gas prices on coal consumption may be analyzed in the absence of unrealistically high price differences across regions. Second, this representation is consistent with the expanding global trade of liquefied natural gas (LNG). Although LNG currently accounts for a minor share of total natural gas consumption, penalties on $\mathrm{CO}_{2}$ emissions can be expected to spur demand for the least carbon-intensive fossil fuel.

Figure 2 shows the gas price index from the 1997 base year through 2100 . The reference gas price scenario is determined endogenously in EPPA based upon domestic resources and imports. This scenario has the highest gas prices rising over four times from a 1997 global average price of $\$ 2.66 / \mathrm{mcf}$ to $\$ 11.71 / \mathrm{mcf}$ in 2050 . The exogenously specified mid gas price scenario exhibits a slower rate of increase and reaches a maximum price of $\$ 8.33 / \mathrm{mcf}$ by 2050 . The low gas price scenario reaches a maximum of $\$ 4.80 / \mathrm{mcf}$ in 2010 and declines to a long-run price of $\$ 4.00 / \mathrm{mcf}$ by 2030 . This scenario was exogenously specified to represent a world in which gas is an abundant and globally traded commodity as suggested in Adelman and Lynch [6].

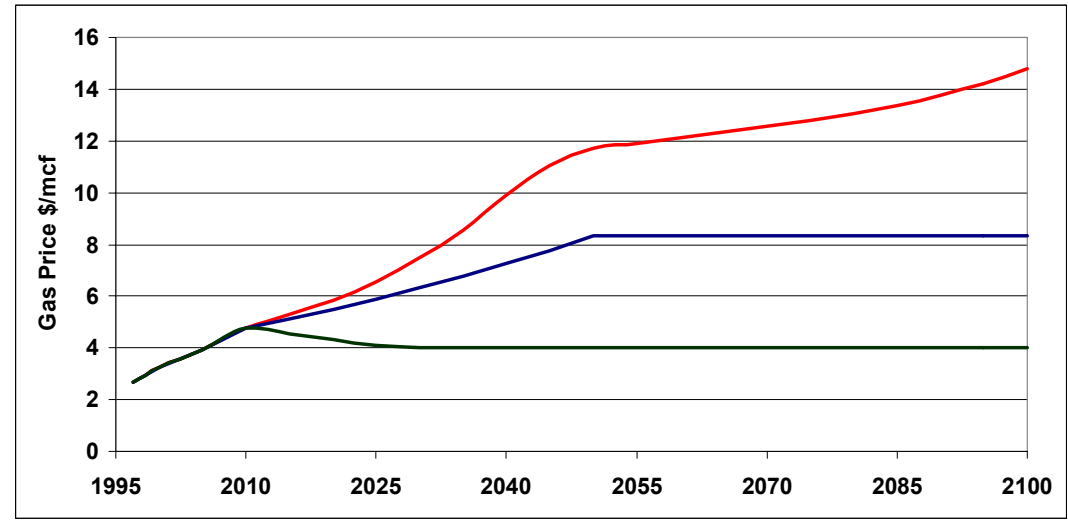

Figure 2 Reference, mid, and low gas price scenarios

\section{Technology costs}

In characterizing CCS technology costs, we extract from bottom-up engineering models the total costs of electricity as delivered to the consumer. We base the generation cost, efficiency, and carbon emissions of CCS technologies on the bottom-up engineering estimates by David and Herzog [7]. Their analysis averages several generation cost studies from the U.S. and Europe. The generation cost data presented herein for reference technology costs reflects their projections of CCS technology costs after modest technical improvements anticipated by 2012 .

The costs of conventional and capture technologies will likely continue to fall over time due to a variety of factors: plant scale, manufacturing scale, improved integration, and learning. To examine the effect of cost reductions in generating technologies on coal consumption, two additional technology cost scenarios are developed (mid- and low -cost). Advances in coal capture technology are greater relative to other technologies because it is less well known and therefore has greater opportunities for improvement. Marginal improvements are also considered for the pulverized coal and advanced gas technologies. 
The estimated costs of electricity generation for the fossil technologies are presented in Table 1 net of emissions penalties. Coal and gas prices are assumed to be $\$ 1.24 / \mathrm{mmBtu}$ and $\$ 3.75 / \mathrm{mmBtu}$, respectively. $\mathrm{CO}_{2}$ injection and storage costs are conservatively assumed to be $\$ 37$ per ton of carbon $(\$ / \mathrm{tC})$ [8]. Additionally, in the table a capacity factor of $80 \%$ is assumed for all technologies and transmission and distribution costs are assumed to be 24.3 mills/kWh [9].

Table 1 Cost of electricity by technology and technology scenario, equal dispatch (mills/kWh)

\begin{tabular}{|l|c|c|c|c|}
\hline $\begin{array}{l}\text { Technology } \rightarrow \\
\text { Scenario } \downarrow\end{array}$ & Pulverized coal & Gas Capture & Coal Capture & Advanced Gas $^{\text {a }}$ \\
\hline $\begin{array}{l}\text { Reference Cost (mills/kWh in 2012) } \\
\text { \% mark-up from PC }\end{array}$ & 62.3 & 74.9 & 80.2 & 61.7 \\
\hline Mid Cost (mills/kWh in 2025) & 60.7 & $+20 \%$ & $+29 \%$ & $-7 \%$ \\
\% mark-up from PC & & $+14 \%$ & $+17 \%$ & \\
\hline Low Cost (mills/kWh beyond 2025) & 60.7 & 65.3 & 67.4 & \\
$\%$ mark-up from PC & $+7 \%$ & $+11 \%$ & \\
\hline Cost with Economic Dispatch & 74.3 & & 65.5 \\
\hline Mid cost 60\% gas capacity factor, & $+22 \%$ & & $-1 \%$ \\
\% mark-up from PC & & & \\
\hline
\end{tabular}

${ }^{\mathrm{a}}$ Compared to electricity from a new pulverized coal unit in 2000-2005 at $66.5 \mathrm{mills} / \mathrm{kWh}$.

\section{Economic dispatch}

In actual power markets, low marginal cost units (e.g., coal units) are dispatched more frequently than higher marginal cost units (e.g., gas units). Thus one would expect coal capture plants to be dispatched ahead of gas capture plants, and therefore, have a higher capacity factor. Bottom-up engineering optimization models with economic dispatch confirm this intuition [10]. The last line in Table 1 shows the electricity costs for advanced gas and gas capture technologies at a $60 \%$ capacity factor.

\section{Results}

\section{Reference case}

In the reference case of the EPPA model, there is no penalty placed on carbon dioxide emissions and natural gas prices are determined endogenously. Coal consumption in the US electric power sector increases from a little over 21 EJ in 2000 to nearly 66 EJ by 2050, a $2.3 \%$ annual increase. Coal accounts for $52 \%$ of primary energy input to the sector in 2000 and expands to $68 \%$ by 2050 . By 2100 coal consumption accounts for over $77 \%$ of the primary energy input to the electric power sector in the US. A similar trend exists in Europe where coal consumption expands from $8.3 \mathrm{EJ}$ in 2000 to $25 \mathrm{EJ}$ by 2050.

\section{Carbon price effects}

As expected, carbon prices have a strong negative impact on coal consumption in 2050. The effect is shown in Figure 3 by plotting coal consumption versus carbon price for the mid technology cost and the three gas price scenarios. Under the low carbon price scenario ( $\$ 170 / \mathrm{tC}$ by 2050) with reference gas prices and mid technology costs, US coal consumption in the electric power sector is reduced by $37 \%$ to $42 \mathrm{EJ}$. At carbon prices of $\$ 340 / \mathrm{tC}$ under the mid carbon price scenario, coal consumption is $34 \mathrm{EJ}$ ( $50 \%$ decrease) and drops to $27 \mathrm{EJ}$ under the high carbon price case $(\$ 500 / \mathrm{tC})$. The European electric power sector (not shown) experiences a slightly less dramatic decline in coal consumption with a reduction in coal consumption of $44 \%$ to $13 \mathrm{EJ}$ under the high carbon price case. 


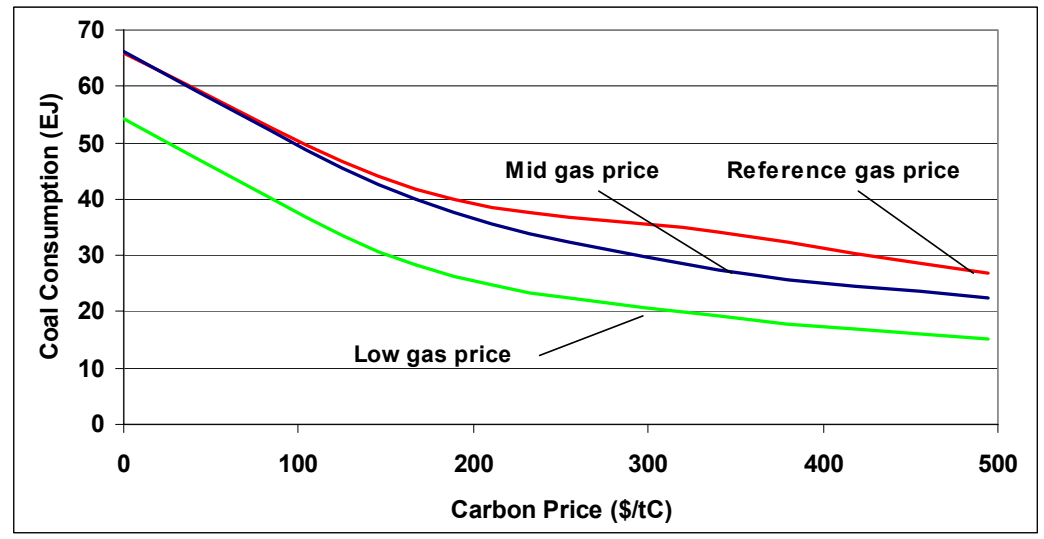

Figure 3 Effect of carbon prices on US coal consumption in 2050

at reference, mid, and low gas prices

\section{Effect of gas prices}

Over the wide ranges examined, the effect of gas price on coal consumption is less significant than the carbon price. This effect is depicted for the US in Figure 3. Under the mid gas price scenario, coal consumption is reduced by 2 to $6 \mathrm{EJ}$ depending on the carbon price. The reduction in coal consumption is much more substantial under the low gas price case. In the absence of any carbon penalty, coal consumption is reduced by 12 EJ. With carbon penalties, the reduction is 11 to $15 \mathrm{EJ}$, or $18-44 \%$ of reference consumption. Again, results for Europe tell a similar story. Mid gas prices lower coal consumption in the electric power sector by roughly 0.5 to $1 \mathrm{EJ}$ or $3-7 \%$ versus the reference gas price path. Low gas prices reduce coal consumption by 2 to $4 \mathrm{EJ}$, or $12-35 \%$.

\section{Effect of technology costs}

Having specified several technology costs scenarios, the scenarios were run with all combinations of carbon prices (high, mid, and low) and gas prices (reference, mid, and low). Under the low carbon price scenario and over all of the gas price scenarios, coal consumption in 2050 is insensitive to variations in technology cost. Coal consumption increases by at most $5 \%$ in response to these vast differences, with minimal generation from the coal capture technology. However, at mid and high carbon prices ( $\$ 340 / \mathrm{tC}$ and $\$ 500 / \mathrm{tC}$ in 2050) lowering technology costs has expected and unexpected consequences in the US. Figure 4 shows the coal consumption in the US electric power sector for all combinations of technology cost and gas price, assuming mid carbon prices.

As illustrated in the previous section, holding technology costs constant, lowering gas price reduces coal consumption. Furthermore, for a given gas price path, lowering technology costs increases the share of coal consumption by the coal capture technology. Under reference technology costs, coal capture accounts for $4-11 \%$ of coal consumption across the three gas scenarios. With the most optimistic technology cost reductions, the coal capture technology accounts for $40-50 \%$ of coal consumption. The effect on total coal consumption is more ambiguous. For reference and mid gas prices, reducing technology costs from reference to mid increases coal consumption by a few percent. However, further cost reductions lower total coal consumption by $4-7 \%$. This reduction in total coal consumption is due to a greater percentage improvement in the gas capture technology. At low gas prices, cost reductions increase generation from gas and lower coal consumption. Thus under reference technology costs and gas prices, coal consumption could grow from 21 EJ in 2000 to 34 EJ by 2050. Alternatively, low technology costs and gas prices would reduce 2050 consumption to $17 \mathrm{EJ}$. 


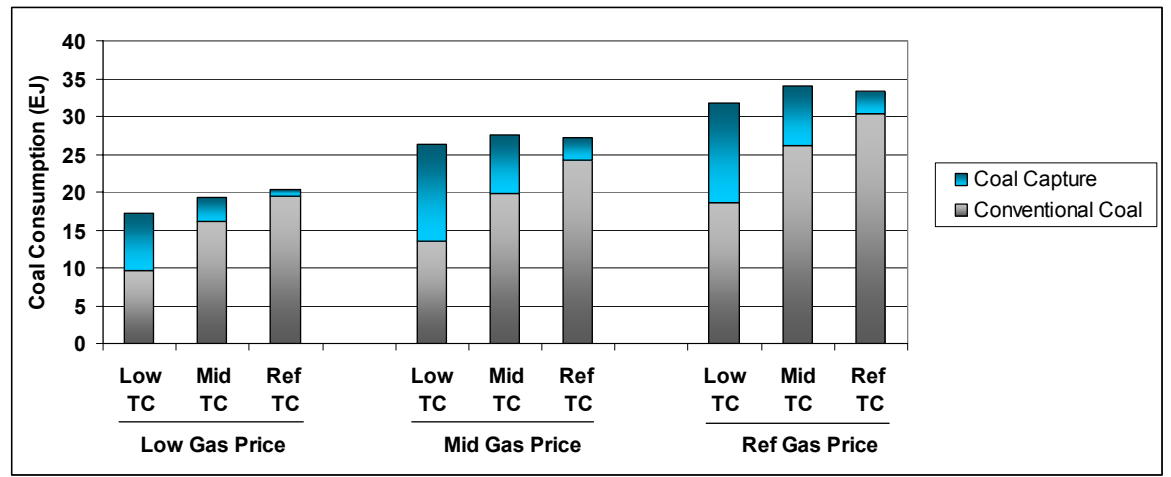

Figure 4 Effect of technology costs on US coal consumption in 2050, mid carbon price scenario

The effect of technology costs on coal consumption in the European electric sector is more straightforward at the reference and mid gas prices. Reductions in technology costs from reference to low increase coal consumption by $6 \%$. Yet the share of coal consumption by the coal capture technology reaches $16 \%$ at most. This is due to the higher thermodynamic efficiency of the European conventional generation technology ( $50 \%$ vs. $45 \%$ for the US). At low gas prices, technology cost reductions favor the gas capture technology and, similar to the US, lower total coal consumption.

\section{Effect of economic dispatch on coal consumption}

Although the analysis above concentrates on the period 2000 through 2050, the effect of economic dispatch is best revealed on a longer time horizon. Figure 5 shows the primary energy inputs into the US electric power sector from 1997 through 2100 under equal dispatch (left panel) and unequal dispatch (right panel) under a mid carbon price, low gas price, mid technology cost scenario. With carbon prices approaching $\$ 450 / \mathrm{tC}$ in the period after 2050 , the gas capture and coal capture technologies dominate electricity production.

By the end of the century at equivalent capacity factors, the gas capture technology consumes 64 EJ of natural gas, more than double the 24 EJ used by the coal capture technology. With only a $60 \%$ capacity factor, as may be the case due to higher marginal costs, the gas capture technology consumes only $36 \mathrm{EJ}$ of natural gas compared to $55 \mathrm{EJ}$ for the coal capture technology. Thus the capacity factor assumption has a profound effect on the long-term technology and fuel choices with low gas prices. At higher gas prices, the coal capture technology has a much larger market share than the gas capture technology regardless of dispatch assumptions.
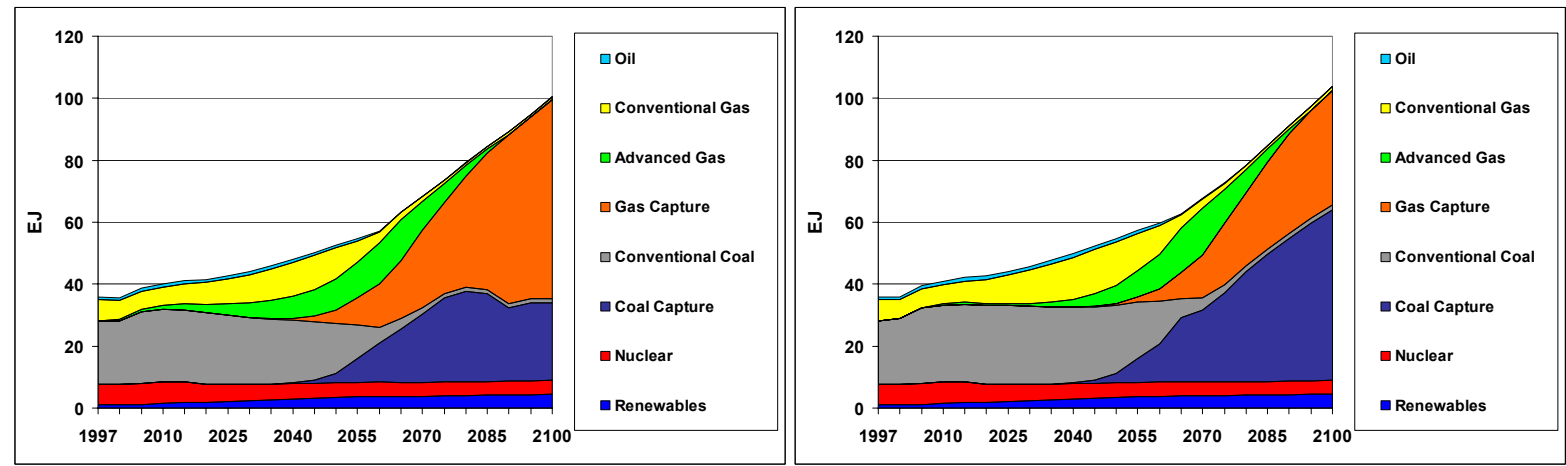

Figure 5 Primary energy consumption in the US electric power sector by technology, mid carbon price, low gas price, mid technology cost, equal (left) and unequal (right) dispatch 


\section{Conclusions}

The US and EU coal industries remains viable in all the cases studied here. However growth opportunities are curtailed to between 0 to $20 \mathrm{EJ}$ for the US and 0 to $8 \mathrm{EJ}$ for the EU from 2000 levels of production for most scenarios. Over the variable ranges tested, coal consumption is most highly dependent upon the carbon price. Coal consumption is less sensitive to natural gas prices than carbon prices over the ranges examined. Improvements in CCS technology make coal consumption less dependent on gas prices but do not mitigate carbon price effects on consumption through 2050. Finally, assumptions on the dispatch of coal and gas plants have a significant impact on coal consumption under low gas prices beyond 2050.

\section{References}

1. Babiker, M., J. Reilly, M. Mayer, R. Eckaus, I. Sue Wing and R. Hyman. 2001. The MIT emissions prediction and policy analysis (EPPA) model: revisions, sensitivities, and comparisons of results, MIT Joint Program on the Science and Policy of Global Change, Report No. 71.

2. Hyman, R. C., J. Reilly, M.H. Babiker, A. De Masin, H.D. Jacoby. 2003. Modeling non-CO2 greenhouse gas abatement. Environmental Modeling and Assessment Vol. 8: 175-86.

3. McFarland, J., J. Reilly and H. Herzog. 2004. Representing energy technologies in top-down economic models using bottom-up information. Energy Economics in press.

4. Reilly, J., H. Jacoby and R. Prinn. 2002. Multi-gas contributors to global climate change: climate impacts and mitigation costs of non- $\mathrm{CO}_{2}$ gases, Pew Center on Global Climate Change, Arlington, VA.

5. Hertel, T. 1997. Global Trade Analysis: Modeling and Applications. Cambridge University Press: Cambridge.

6. Adelman, M.A. and M.C. Lynch. 2002. Natural gas supply to 2100. International Gas Union, October.

7. David, J. and H. Herzog. 2000. The cost of carbon capture, presented at the Fifth International Conference on Greenhouse Gas Control Technologies, Cairns, Australia.

8. Bock, B., R. Rhudy, H. Herzog, M. Klett, J. Davison, D. De La Torre, D. Simbeck. 2003. Economic evaluation of $\mathrm{CO}_{2}$ storage and sink enhancement options, TVA Public Power Institute Technical Report, February.

9. U.S. Department of Energy, 1999. Supporting analysis for the Comprehensive Electricity Competition Act. Office of Economic, Electricity and Natural Gas Analysis and Office of Policy, Report no. DOE/PO-0059, May.

10. Johnson, T.L. and D.W. Keith. 2003. Fossil electricity and $\mathrm{CO}_{2}$ sequestration: how natural gas prices, initial conditions and retrofits determine the cost of controlling $\mathrm{CO}_{2}$ emissions. Energy Policy Vol. 32, No. 3: $367-82$. 